\title{
Clinical Study \\ Hepatic Steatosis, Carbohydrate Intake, and Food Quotient in Patients with NAFLD
}

\author{
Concepcion Gonzalez, ${ }^{1}$ Victor de Ledinghen, ${ }^{1}$ Julien Vergniol, ${ }^{1}$ Juliette Foucher, ${ }^{1}$ \\ Brigitte Le Bail, ${ }^{2}$ Sabrina Carlier, ${ }^{1}$ Elisa Maury, ${ }^{1}$ Henri Gin, ${ }^{1}$ and Vincent Rigalleau ${ }^{1,3}$ \\ ${ }^{1}$ Pôle Hépatogastroentérologie, Endocrinologie et Nutrition, CHU de Bordeaux, Avenue de Magellan, 33600 Pessac, France \\ ${ }^{2}$ Service de Pathologie, CHU de Bordeaux, France \\ ${ }^{3}$ INSERM, ISPED, Centre INSERM U897-Epidemiologie-Biostatistique, 33000 Bordeaux, France
}

Correspondence should be addressed to Vincent Rigalleau; vincent.rigalleau@chu-bordeaux.fr

Received 11 January 2013; Accepted 12 April 2013

Academic Editor: Kaori Minehira

Copyright (C) 2013 Concepcion Gonzalez et al. This is an open access article distributed under the Creative Commons Attribution License, which permits unrestricted use, distribution, and reproduction in any medium, provided the original work is properly cited.

\begin{abstract}
Is steatosis related to the spontaneous carbohydrate intake in patients with NAFLD? We performed dietary records for 24 patients with NAFLD, 3 months after their liver biopsy was performed and before the deliverance of a dietary advice. The food quotient, indicator of the proportion of calories from carbohydrates, was calculated as $(1.00 \times \%$ calories from carbohydrates $/ 100)+$ $(0.70 \times \%$ calories from lipids $/ 100)+(0.81 \times \%$ calories from proteins $/ 100)$. The associations between diet variables and steatosis\% on the hepatic biopsies were tested by regression analysis, and diet variables were compared according to the presence of fibrosis. The subjects displayed a large range of steatosis, $50.5 \% \pm 25.5$ [10-90], correlated with their energy intake $(1993 \pm 597 \mathrm{kcal} / \mathrm{d}, r=0.41$, $P<0.05)$ and food quotient $(0.85 \pm 0.02, r=0.42, P<0.05)$, which remained significant with both variables by a multivariate regression analysis $(r=0.51, P<0.05)$. For the $17 / 24$ patients with a hepatic fibrosis, the energy intake was lower (fibrosis: $1863 \pm 503$ versus others: $2382 \pm 733 \mathrm{kcal} / \mathrm{d}, P<0.05)$, and their food quotients did not differ from patients without fibrosis. Hepatic steatosis was related to the energy and carbohydrate intakes in our patients; the role of dietary carbohydrates was detectable in the range of usual carbohydrate intake: $32 \%$ to $58 \%$ calories.
\end{abstract}

\section{Introduction}

The high prevalence of nonalcoholic fatty liver diseases (NAFLD) is now well recognized, involving 15\% (ultrasound study in China [1]) to $34 \%$ (MR spectroscopy in the USA [2]) of adults. Not only serious late consequences, as liver fibrosis [3] and hepatocellular carcinoma [4], but also high rates of cardiovascular events [5], make NAFLD a relevant public health issue. Lifestyle modifications, predominantly dietary, are considered as the first line of the therapy [6]; however, beside the importance of losing excessive weight, the dietary counselling for NAFLD is not consensual, as reflected by several recent reviews [7-9]. The reduction of liver fat is a logical objective, $26 \%$ of which arise from De Novo Lipogenesis and $15 \%$ from the diet, so less dietary carbohydrates and/or lipids may help [10]; however, their proportion is debatable.
The Nutrition and Hepatology Teams of the Centre Hospitalier Universitaire de Bordeaux cooperatively follow patients with NAFLD: once the diagnosis of NAFLD is stated by the hepatologist, the patients are referred to the Nutrition Team; they are interviewed by a dietician before the delivery of dietary advice. This gave us the opportunity to test whether the degree of steatosis and the presence of hepatic fibrosis could be related to their spontaneous energy intake and to the proportion of energy from carbohydrate, as reflected by the food quotient.

\section{Materials and Methods}

The dietary interviews were performed by dieticians, who performed a seven-day recall of dietary intakes, using a BillNutIV software for the analysis of the nutrient intakes, in 24 patients with NAFLD, $3 \pm 2$ months after their hepatic 
biopsy was performed, and before the deliverance of a dietary advice. Other causes of liver diseases (virus and drugs) were excluded, as were the subjects who declared an excessive alcohol consumption ( $>20 \mathrm{~g} / \mathrm{d}$ for women and $30 \mathrm{~g} / \mathrm{d}$ for men) and the subjects who had known diabetes that might have led them to restrain their carbohydrate intake.

The food quotient, indicator of the proportion of calories from carbohydrates, was calculated as $(1.00 \times \%$ calories from carbohydrates $/ 100)+(0.70 \times \%$ calories from lipids $/ 100)+$ $(0.81 \times \%$ calories from proteins $/ 100)$ [11].

Steatosis was evaluated by a senior pathologist as a percent of hepatocytes containing fat droplets, either macrovacuolar or microvascular, on liver sections stained with HES (hematin-eosin-saffron) of transparietal liver biopsies. The presence or absence of fibrosis (any stage, including cirrhosis) was evaluated histologically by the same pathologist, using Masson's trichromic stain.

The associations between diet variables and steatosis\% on the hepatic biopsies were tested by regression analysis, and diet variables were compared according to the presence of fibrosis on the biopsies.

\section{Results and Discussion}

Twenty-four subjects ( 15 men, 9 women, age $45 \pm 13$ yrs) were referred to the Nutrition Team after the diagnosis of NAFLD was stated on a liver biopsy. They were overweight (BMI: 29.7 \pm 3.8 ; waist circumference: men $100 \pm 7 \mathrm{~cm}$; women $100 \pm 8 \mathrm{~cm}$ ), with abnormal liver tests (ALAT: $72 \pm 53 \mathrm{IU} / \mathrm{L}$, GGT: $117 \pm 98 \mathrm{IU} / \mathrm{L})$. According to the exclusion criteria, they were not known as diabetic (fasting glycemia: $5.4 \pm 0.8 \mathrm{mM}$ ), and their alcohol intake was below the recommended limits in France: mean $2 \pm 5 \mathrm{~g} /$ day.

The steatosis\% was $50.5 \pm 25.5$ [10-90]. The relations between the steatosis\% on the hepatic biopsy and the dietary calorie intake (kcal/day) and the food quotient were both significant $(r=0.41$ and 0.42 , resp., both $P<0.05)$ as depicted in Figures 1(a) and 1(b) $(r=0.51, P=0.039$ with both by multivariate regression analysis). This confirms that less calories and less carbohydrates in the diet are associated with less fat in the liver of the patients with NAFLD. The steatosis\% was also correlated to the carbohydrate intakes expressed as grams/day ( $r=0.49, P=0.015$, Figure $1(\mathrm{c})$ ), whereas the correlations with the intakes of lipids $(r=0.15)$, proteins $(r=0.30)$ and simple sugars $(r=0.10)$ were all far from significance. De novo lipogenesis is considered as a small contributor to the accumulation of fat in the whole body [12], but several investigators have reported that it may be an important contributor for liver fat [13-15], and two recent reports using proton magnetic resonance spectroscopy emphasized this importance. Browning et al. demonstrated a greater reduction of hepatic triglycerides after 2 weeks on a low-carbohydrate diet ( $26 \mathrm{~g}$ carbohydrates/day) than during a $50 \%$ carbohydrate low-calorie diet in 18 patients with NAFLD [16]. On the other hand, Sevastianova et al. have shown that only three weeks of carbohydrates overfeeding could increase liver fat by $+27 \%$ contrasted with a $+2 \%$ body weight gain [17]. In our patients, the relation
TABLE 1: Comparison of the subjects with versus without liver fibrosis.

\begin{tabular}{lccc}
\hline & With fibrosis & No fibrosis & $P$ \\
\hline$n$ & 17 & 7 & \\
Men & 10 & 5 & NS \\
Age (yrs) & $49 \pm 11$ & $34 \pm 12$ & $<0.05$ \\
ALAT (IU/L) & $50 \pm 23$ & $127 \pm 69$ & $<0.001$ \\
GGT (IU/L) & $125 \pm 98$ & $95 \pm 102$ & NS \\
Fasting glycaemia & $5.5 \pm 0.7$ & $5.1 \pm 0.4$ & NS \\
(mmol/L) & & & \\
Steatosis\% on the hepatic & $45 \pm 25$ & $63 \pm 21$ & NS \\
biopsy & $30.6 \pm 3.4$ & $27.4 \pm 4.0$ & NS $(0.06)$ \\
$\begin{array}{l}\text { Body Mass Index (kg/m }{ }^{2} \text { ) } \\
\text { Maximal BMI during life }\end{array}$ & $33.2 \pm 3.4$ & $28.7 \pm 4.0$ & $<0.01$ \\
Waist circumference (cm) & $101 \pm 8$ & $96 \pm 6$ & NS \\
$\begin{array}{l}\text { Energy intake (kcal/day) } \\
\text { Carbohydrate intake }\end{array}$ & $1863 \pm 503$ & $2382 \pm 73$ & $<0.05$ \\
(grams/day) & $204 \pm 63$ & $290 \pm 117$ & $<0.05$ \\
$\begin{array}{l}\text { Simple sugars (grams/day) } \\
\text { Lipid intakes (grams/day) }\end{array}$ & $70 \pm 40$ & $103 \pm 60$ & NS \\
$\begin{array}{l}\text { Protein intakes } \\
\text { (grams/day) }\end{array}$ & $88 \pm 20$ & $110 \pm 32$ & NS (0.06) \\
Food quotient & $0.85 \pm 0.02$ & $0.86 \pm 0.01$ & NS \\
\hline
\end{tabular}

between liver fat and dietary carbohydrates applied to a more usual range of carbohydrate proportion: our extreme food quotients were 0.82 (33\% carb, $44 \%$ lipids, $23 \%$ protein, and $20 \%$ liver steatosis) and 0.89 (58\% carb, 30\% lipids, $12 \%$ protein, and $80 \%$ liver steatosis), which suggests that even moderate reductions of dietary carbohydrate may help to reduce liver fat in NAFLD. However, hepatic steatosis is, by itself, a benign condition [18], and the real offends are hepatic inflammation and fibrosis that may not rely on the same mechanisms.

Seventeen of the 24 patients had liver fibrosis, their characteristics are compared to those of nonfibrotic patients in Table 1. In our patients, fibrosis was not related to high calorie intakes, that were even lower $(1860 \pm 471 \mathrm{kcal} /$ day versus $2380 \pm 690$ if no fibrosis, $P<0.05$ ), or to food quotients, that did not differ (fibrosis: $0.85 \pm 0.02$, no fibrosis: $0.86 \pm 0.02$, NS). The older age of the patients with fibrosis may have contributed to both their lower calorie intakes and to their hepatic fibrosis as their exposure to steatosis had a presumably longer duration. These negative results do not question the interest of a well-balanced weightlosing lifestyle intervention, which was proven to improve steatosis and inflammation by a randomized controlled trial [19]. Because our effective was limited, we cannot rule out that very high intakes [20] or some specific forms of carbohydrates like fructose [21] may favor hepatic fibrosis. But by contrasting this with the relation to the steatosis\%, we failed to detect a change in the lipid/glucide proportion in our patients with fibrosis; their absolute carbohydrate intakes were even significantly lower as shown in Table 1. 


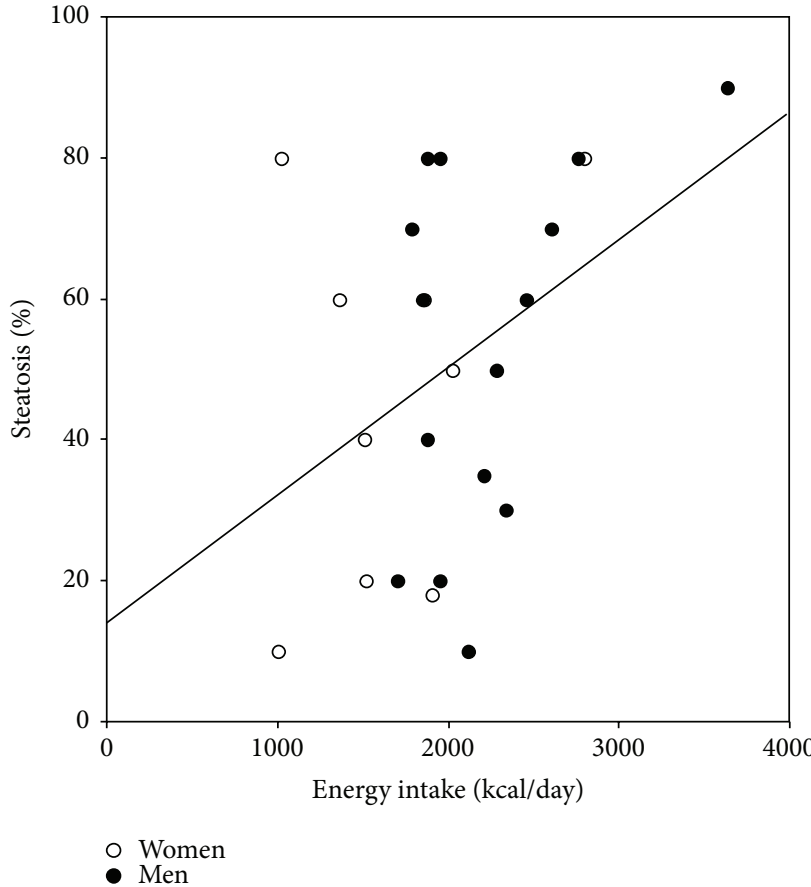

(a)

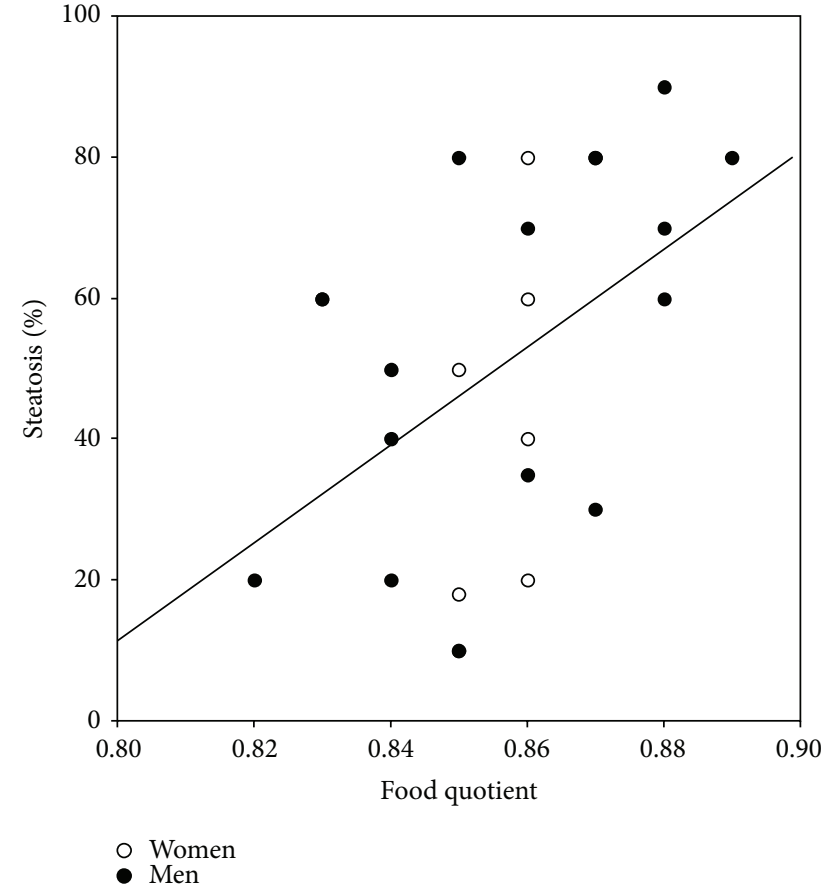

(b)

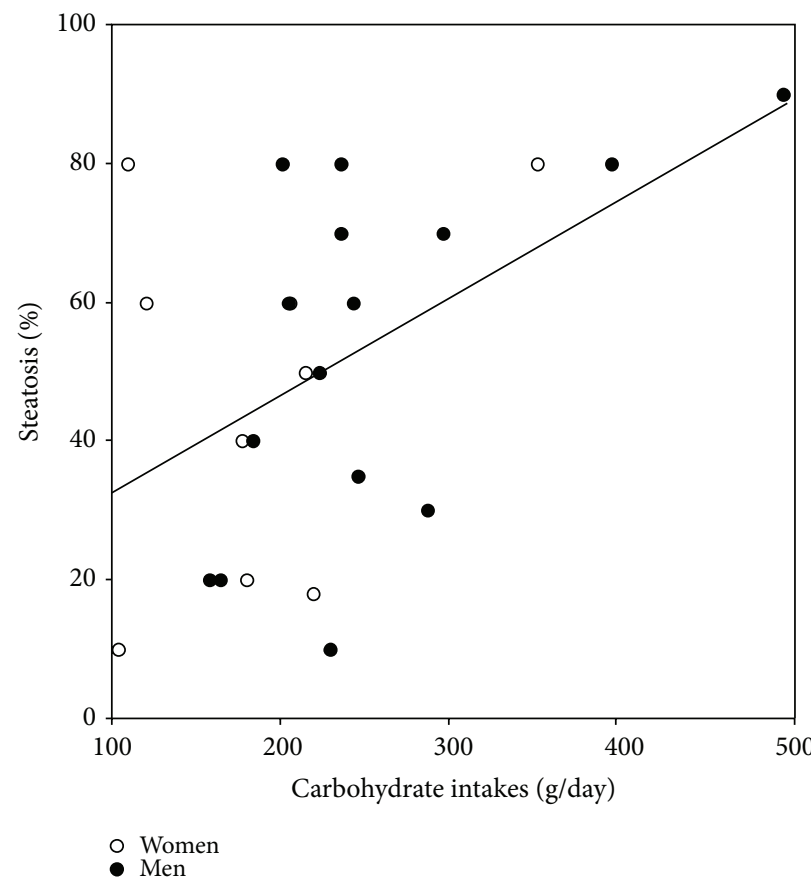

(c)

FIGURE 1: Steatosis\% ( $y$-axis) as a function of the energy intakes ( $x$-axis, (a)), food quotients ( $x$-axis, (b)), and carbohydrate intakes $(x$-axis, (c)) in 24 patients with NAFLD (women-open circles, men-closed circles).

On the long term, very low-carbohydrate diets are limited by high attrition rates [22] and a questionable risk of coronary heart disease [23]. We therefore feel that reducing carbohydrate is an interesting track in the field of NAFLD, but it needs caution for a generalized long-term application.

\section{Conclusions}

Hepatic steatosis was related to the energy and carbohydrate intakes in our patients. The role of dietary carbohydrates was detectable in the range of usual intake: $32 \%$ to $58 \%$ calories from carbohydrates, but the energy intakes and the 
food quotients were not higher in the patients with hepatic fibrosis, the real offender. More information seems required before considering that reducing carbohydrates from the diet is beneficial on the long term in patients with NAFLD.

\section{Acknowledgment}

The authors thank Florence Garuz and Delphine Sury, who performed the dietary interviews.

\section{References}

[1] J. G. Fan, J. Zhu, X. J. Li et al., "Prevalence of and risk factors for fatty liver in a general population of Shanghai, China," Journal of Hepatology, vol. 43, no. 3, pp. 508-514, 2005.

[2] J. D. Browning, L. S. Szczepaniak, R. Dobbins et al., "Prevalence of hepatic steatosis in an urban population in the United States: impact of ethnicity," Hepatology, vol. 40, no. 6, pp. 1387-1395, 2004.

[3] V. de Lédinghen, V. Ratziu, X. Causse et al., "Diagnostic and predictive factors of significant liver fibrosis and minimal lesions in patients with persistent unexplained elevated transaminases. A prospective multicenter study," Journal of Hepatology, vol. 45, no. 4, pp. 592-602, 2006.

[4] V. Paradis, S. Zalisnski, E. Chelbi et al., "Hepatocellular carcinomas in patients with metabolic syndrome often develop without significant liverfibrosis: a pathological analysis," Hepatology, vol. 49, no. 3, pp. 851-859, 2009.

[5] Y. C. Lin, H. M. Lo, and J. D. Chen, "Sonographic fatty liver, overweight and ischemic heart disease," World Journal of Gastroenterology, vol. 11, no. 31, pp. 4838-4842, 2005.

[6] B. A. Neuschwander-Tetri, "Lifestyle modification as theprimary treatment of NASH," Clinics in Liver Disease, vol. 13, no. 4, pp. 649-665, 2009.

[7] V. Ratziu, S. Bellentani, H. Cortez-Pinto, C. Day, and G. Marchesini, "A position statement on NAFLD/NASH based on the EASL 2009 special conference," Journal of hepatology, vol. 53, no. 2, pp. 372-384, 2010.

[8] K. Yasutake, M. Kohjima, M. Nakashima, K. Kotoh, M. Nakamuta, and M. Enjoji, "Nutrition therapy for liver diseases based on the status of nutritional intake," Gastroenterology Research and Practice, vol. 2012, Article ID 859697, 8 pages, 2012.

[9] C. Finelli and G. Tarantino, "Is there any consensus as to what diet or lifestyle approach is the right one for NAFLD patients?" Journal of Gastrointestinal and Liver Diseases, vol. 21, pp. 293302, 2012.

[10] K. L. Donnelly, C. I. Smith, S. J. Schwarzenberg, J. Jessurun, M. D. Boldt, and E. J. Parks, "Sources of fatty acids stored in liver and secreted via lipoproteins in patients with nonalcoholic fatty liver disease," Journal of Clinical Investigation, vol. 115, no. 5, pp. 1343-1351, 2005.

[11] K. R. Westerterp, M. A. Crawford, E. Ravussin, and M. Katan, "Food quotient, respiratory quotient, and energy balance," American Journal of Clinical Nutrition, vol. 57, no. 5, pp. S759S765, 1993.

[12] M. K. Hellerstein, "No common energy currency: de novo lipogenesis as the road less traveled," American Journal of Clinical Nutrition, vol. 74, no. 6, pp. 707-708, 2001.

[13] R. M. McDevitt, S. J. Bott, M. Harding, W. A. Coward, L. J. Bluck, and A. M. Prentice, "De novo lipogenesis during controlled overfeeding with sucrose or glucose in lean and obese women," American Journal of Clinical Nutrition, vol. 74, no. 6, pp. 737746, 2001.

[14] F. Diraison, P. H. Moulin, and M. Beylot, "Contribution of hepatic de novo lipogenesis and reesterification of plasma non esterified fatty acids to plasma triglyceride synthesis during non-alcoholic fatty liver disease," Diabetes and Metabolism, vol. 29, no. 5, pp. 478-485, 2003.

[15] D. Faeh, K. Minehira, J. M. Schwarz, R. Periasami, P. Seongsu, and L. Tappy, "Effect of fructose overfeeding and fish oil administration on hepatic de novo lipogenesis and insulin sensitivity in healthy men," Diabetes, vol. 54, no. 7, pp. 1907-1913, 2005.

[16] J. D. Browning, J. A. Baker, T. Rogers, J. Davis, S. Satapati, and S. C. Burgess, "Short-term weight loss and hepatic triglyceride reduction: evidence of a metabolic advantage with dietary carbohydrate restriction," American Journal of Clinical Nutrition, vol. 93, no. 5, pp. 1048-1052, 2011.

[17] K. Sevastianova, A. Santos, A. Kotronen et al., "Effect of shortterm carbohydrate overfeeding and long-term weight loss on liver fat in overweight humans," American Journal of Clinical Nutrition, vol. 96, pp. 727-734, 2012.

[18] M. R. Teli, O. F. W. James, A. D. Burt, M. K. Bennett, and C. P. Day, "The natural history of nonalcoholic fatty liver: a follow-up study," Hepatology, vol. 22, no. 6, pp. 1714-1719, 1995.

[19] K. Promrat, D. E. Kleiner, H. M. Niemeier et al., "Randomized controlled trial testing the effects of weight loss on nonalcoholic steatohepatitis (NASH)," Hepatology, vol. 51, no. 1, pp. 121-129, 2010.

[20] G. Ricci, E. Canducci, V. Pasini et al., "Nutrient intake in Italian obese patients: relationships with insulin resistance and markers of non-alcoholic fatty liver disease," Nutrition, vol. 27, no. 6, pp. 672-676, 2011.

[21] M. F. Abdelmalek, A. Suzuki, C. Guy et al., "Increased fructose consumption is associated with fibrosis severity in patients with nonalcoholic fatty liver disease," Hepatology, vol. 51, no. 6, pp. 1961-1971, 2010.

[22] I. Shai, D. Schwarzfuchs, Y. Henkin et al., "Weight loss with a low-carbohydrate, Mediterranean, or low-fat diet," New England Journal of Medicine, vol. 35, pp. 229-241, 2008.

[23] A. M. Zivkovic, J. B. German, and A. J. Sanyal, "Comparative review of diets for the metabolic syndrome: implications for nonalcoholic fatty liver disease," American Journal of Clinical Nutrition, vol. 86, no. 2, pp. 285-300, 2007. 


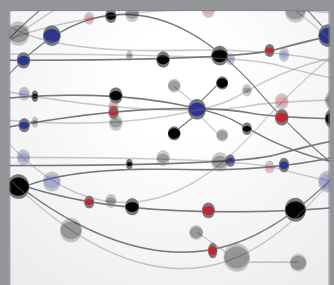

The Scientific World Journal
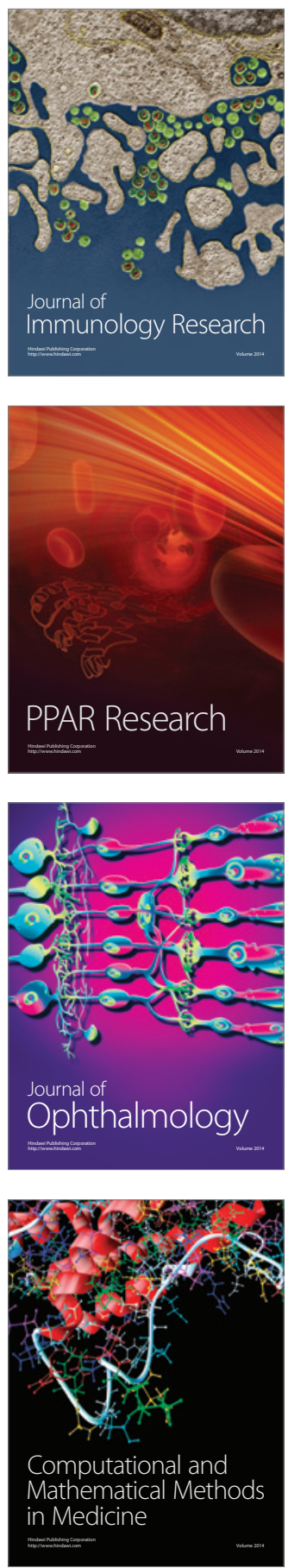

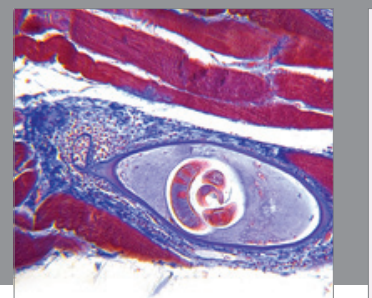

Gastroenterology

Research and Practice
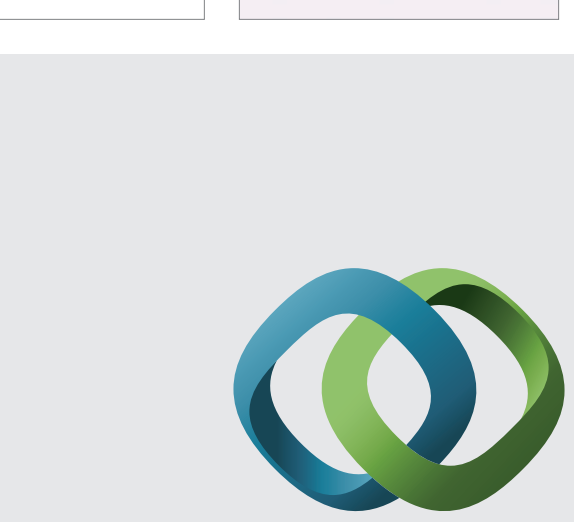

\section{Hindawi}

Submit your manuscripts at

http://www.hindawi.com
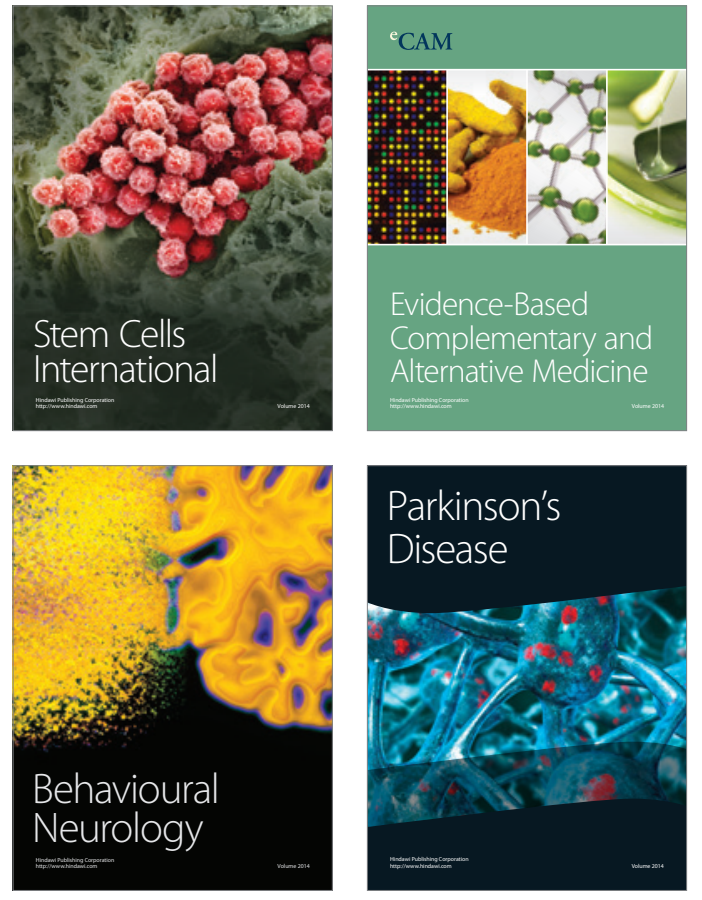
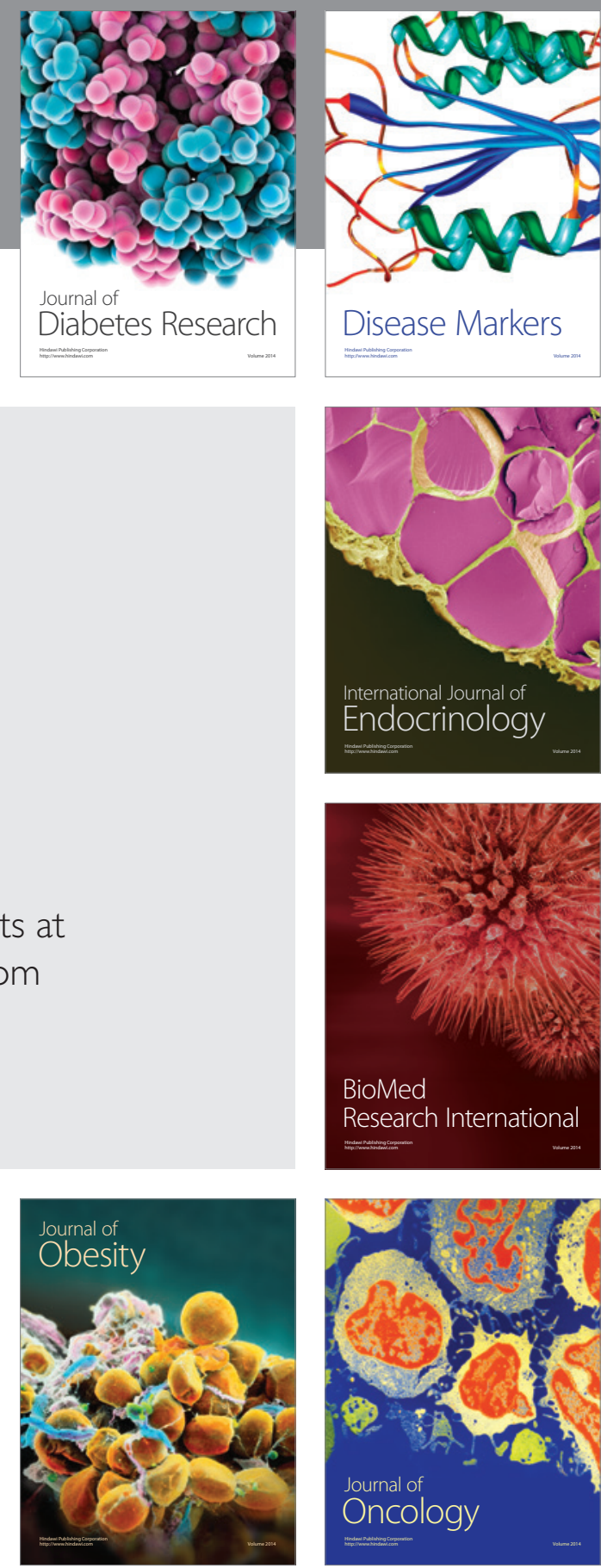

Disease Markers
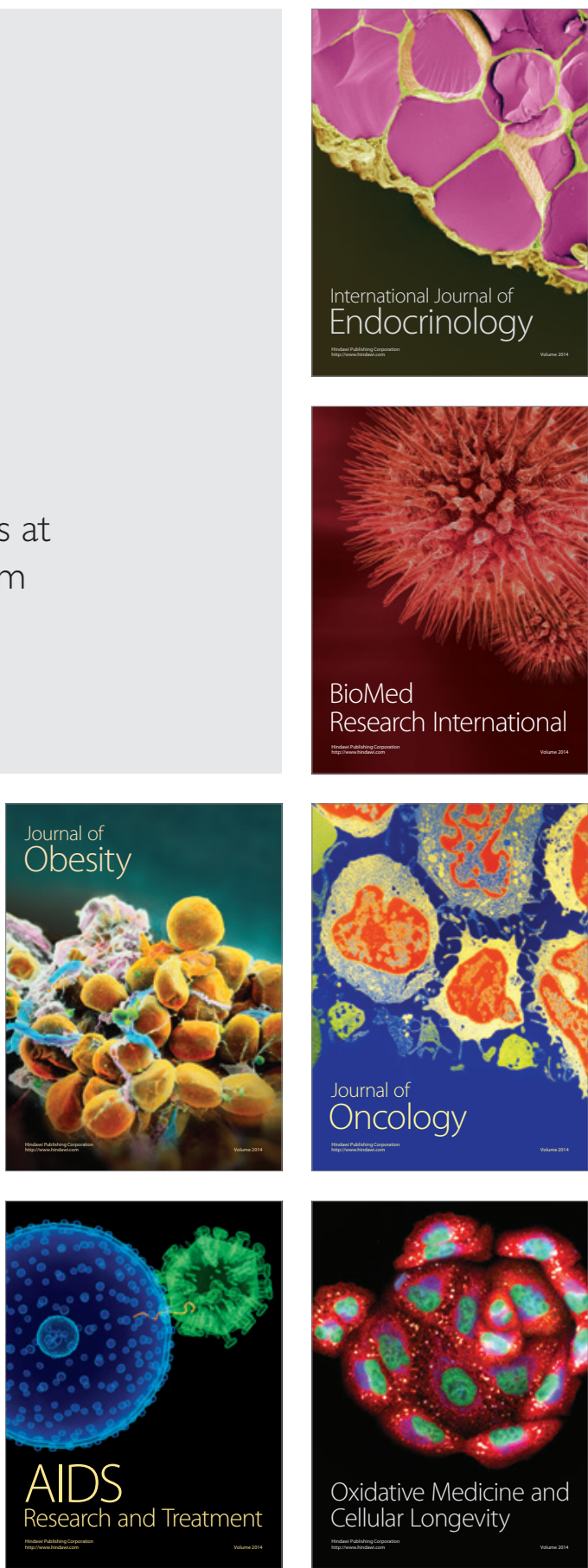